\title{
Water service delivery challenges in a small South African municipality: Identifying and exploring key elements and relationships in a complex social-ecological system
}

\author{
MJT Weaver', J O'Keeffe ${ }^{2}$, N Hamer ${ }^{1}$ and CG Palmer ${ }^{1}$ \\ 'Institute for Water Research (IWR), Rhodes University, Old Geology Building, Rhodes University, PO Box 94, Grahamstown 6140, South Africa \\ 2Environmental Learning Research Centre, Rhodes University, PO Box 94, Grahamstown 6140, South Africa
}

ABSTRACT
South Africa is a developing country undergoing social and ecological transformation. Water service
delivery (i) exemplifies the challenge of improvement and transformation towards a more socially and
ecologically just situation, and (ii) can usefully be viewed as a complex social-ecological system (C-SES) in
the search for 'just transitions'. Household water security problems associated with water service delivery in
South Africa are recognisably intractable, multi-scaled, comprising many actors and elements and having
no single solution. There is a global and South African trend towards systemic approaches to addressing
such complex water challenges. However, the steps required to take a systemic approach are seldom explicit.
This paper presents the analytical process of defining boundaries, identifying elements and exploring
relationships between elements as the foundational step in a study of the Makana Local Municipality water
service delivery C-SES in the Eastern Cape Province of South Africa. The resulting narrative and heuristics
provide a clear systemic basis from which to research the emergence, practice and social learning process
of a civil society organisation (Water for Dignity) seeking to confront water service delivery issues in the
Makana Local Municipality.
Keywords: complex adaptive systems, systems inquiry, household water service delivery,
civil society organisation

\section{INTRODUCTION}

For at least two decades, the fair provision of adequate water services to all in an ecologically sustainable and economically efficient manner has been a high priority in South Africa (RSA, 1998; DWA, 2013). Water management systems are complex as they comprise environmental, human, economic and technological elements (Pahl-Wostl, 2007; Slinger et al., 2011) with non-linear interactions, inherent feedbacks, and scale-sensitive processes, and are thus prone to unpredictable outcomes (Cilliers, 2000). Problems associated with water management systems are therefore inherently complex and not conducive to reductionist problem-solving approaches (Cilliers et al., 2013). Consequently, negotiating a 'just transition' (Swilling and Annecke, 2012) from an unjust Apartheid system to a situation where household water supply is reliable, sustainable and equitable has been a challenge faced by many South African municipalities and requires a shift from past unsuccessful approaches (Folke, 2003; Biswas, 2008) to more novel approaches (Rogers et al., 2013).

As a result, some researchers, policy makers and managers engaging with these complex problems are increasingly adopting integrated and systems approaches (Ison, 2010; Lang et al., 2012) and developing and taking on useful concepts such as strategic adaptive management (Rogers and Luton, 2011) and complex social-ecological systems (Berkes et al., 2003; Biggs et al., 2015).
Despite the burgeoning growth in complex socialecological systems (C-SES) theory and thinking (Berkes et al., 2003; Pollard and Toit, 2008), there is less focus in the literature on translating this theory into practice. Ison (2010) has gone some way to review and present systems practice in the context of social-ecological challenges related to global climate change. This paper seeks to set out important initial steps for researchers engaging in complex social-ecological systems (C-SES) inquiry, steps that are not made clear in the literature. We demonstrate a methodology for initial steps in engaging in C-SES inquiry in the context of household water service delivery in the case of the Makana Local Municipality in the Eastern Cape of South Africa.

The paper has two specific aims: (i) to demonstrate a methodology for defining the bounds and identifying key elements and relationships in a C-SES; and (ii) to demonstrate this methodology through the example of a case study. The second aim is addressed through a rich contextual description and analysis of the Makana Local Municipality water management system (from here on referred to as the MLM C-SES). The case study provides the foundation for addressing pertinent questions related to practice, learning and transformation associated with household water supply in the MLM C-SES.

\footnotetext{
To whom all correspondence should be addressed

+27 46 603-7687; e-mail: mjtweaver@gmail.com Received 23 June 2016; accepted in revised form 6 June 2017
} 


\section{A 'SYSTEMS' APPROACH METHODOLOGY}

To understand, measure and (or) evaluate change-oriented interventions into challenged C-SESs, it is important to have a basic understanding of the complex system itself. A systems approach allows an exploration of inter-relationships (key to understanding the behaviour of a system), diverse and novel perspectives (for example, insights into people's behaviour in a system) and for establishing study boundaries (decisions regarding who and what is included and, therefore, who benefits and who loses out at a defined scale of decisionmaking, what should be focused on and what should not so as to improve understanding of a specific issue at a specific scale and to ultimately enhance the effectiveness of an intervention) (Williams and Van 't Hof, 2016).

Defining a situation of interest is an important starting point for a systems inquiry and can be a general area of interest, a problem of interest or a potential solution to a problem (Williams and Van 't Hof, 2016). The general situation of interest described here is unreliable household water service delivery at a local government scale. This situation can be viewed as the purpose of a system, which Ison (2010 p. 44) describes as 'a collection of entities that are seen by someone as interacting together to do something'. Related entities or elements can be grouped into sub-systems, each comprising their own interacting elements. For example, the situation of household water service delivery is a function of a water management social-ecological system that comprises interdependent:

- Human systems - water-related organisations, technical specialists and water use sectors

- Technical infrastructure - including dams, reticulation piping, pumps and water and sewage treatment works

- Ecological systems (or ecological infrastructure (Bristow et al., 2010)) - including physical components such as the hydrological cycle, physical catchments as well as biological components such as aquatic, riparian and terrestrial ecosystems within a catchment, and biogeochemical components driving processes in the water system

As complex systems are impossible to understand or explore in their entirety, it is more effective to focus on a limited number of components (Cilliers et al., 2013). Deciding what falls within and out of a system is the next important step in a systems inquiry. Ison (2010) emphasised the importance of subjectively bounding a system, in order to focus on certain sub-systems of interest. Bounding the system is guided by the situation of interest and shows what the observer believes to be important components of the system. Accordingly, there are multiple ways that a system could be understood, depending on the perspective of the observer and the particular understanding sought by the study.

The next step in a systems inquiry is identifying key elements and relationships in a system. Understanding the relationality between elements in a system, more so than the nature of elements, is fundamental to systems inquiry and change (Palmer et al., 2015).

This paper demonstrates the foundational steps of a systems inquiry through the case of the Makana Local Municipality water management C-SES: namely, defining the situation of interest, bounding the system, identification of key elements and relationships, and describing key problematic relationships. These steps are supported with a sequence of diagrammatic heuristics and supporting descriptions that contribute to a rich interpretation of the MLM C-SES. Heuristics comprise a method of reducing cognitive effort to enhance decision making (Shah and Oppenheimer, 2008). Systems diagrams, maps and multiple cause or causal loop diagrams are heuristics that capture the understanding of a systems practitioner and serve as a useful mediating tool to communicate this understanding with others (Ison, 2010).

An emergent outcome of this C-SES analysis was the development of a systems overview heuristic of the MLM C-SES. It was the engagement in the systems inquiry process (sustained time engaged in the system, observing changing social relationships, practice and understanding) and process of defining and articulating the MLM C-SES that resulted in the emergent development of the MLM C-SES heuristic.

\section{CASE STUDY}

\section{The case of Makana Local Municipality water management complex social-ecological system (MLM C-SES)}

To understand issues related to household water supply at the local scale of the Makana Local Municipality it was important to understand the national scale context of water service delivery. In South Africa, the fundamental principles for protecting and managing water resources are: equity, sustainability and efficiency (RSA, 1998). These principles guide the core objective of water service management systems, namely, to reliably supply users with sufficient quality and quantity of water (RSA, 1997). The Department of Water and Sanitation (DWS) put this objective eloquently with their early slogan - 'some for all, forever' - that captured the principles for equitably distributing a finite resource while redressing historical imbalances (King and Pienaar, 2011). Although this was a national slogan and commitment, the Constitution of 1996 deemed the responsibility for ensuring its realisation in practice to be that of the most local levels of government metropolitan, district and local municipalities (RSA, 1996). The municipalities throughout South Africa that are most challenged with the responsibility of household water supply are 'local' or Category B2 municipalities (Clifford-Holmes, 2015), which are defined as local municipalities with large towns as their core (MDB, 2013). Townships, which refer to urban sections of towns that during Apartheid were set aside for Black residents and received minimal service provision infrastructure, are particularly challenged in terms of water service delivery (WSD) (Jürgens et al., 2013). Through a systems thinking lens, townships can viewed as sub-systems of cities and towns.

The MLM is a clear example of a WSD-challenged Category B2 municipality. This case study focused on WSD in the township area of the city of Grahamstown (the urban core of the MLM), locally known as Grahamstown East (Fig. 1). It is in Grahamstown East that water service delivery failure is hardest felt as it harbours the majority of Grahamstown's population, many of whom are poor and lack the capacity (financial and social capital) to mitigate against water supply shortfall.

Contributing to the complexity of WSD in the MLM are the municipality's responsibilities to several other smaller urban centres outside of its high-population urban core, Grahamstown. These other centres all require municipal support but are often neglected as the municipality focuses much of its attention inwards on Grahamstown's numerous challenges, of which water supply and quality are particularly 


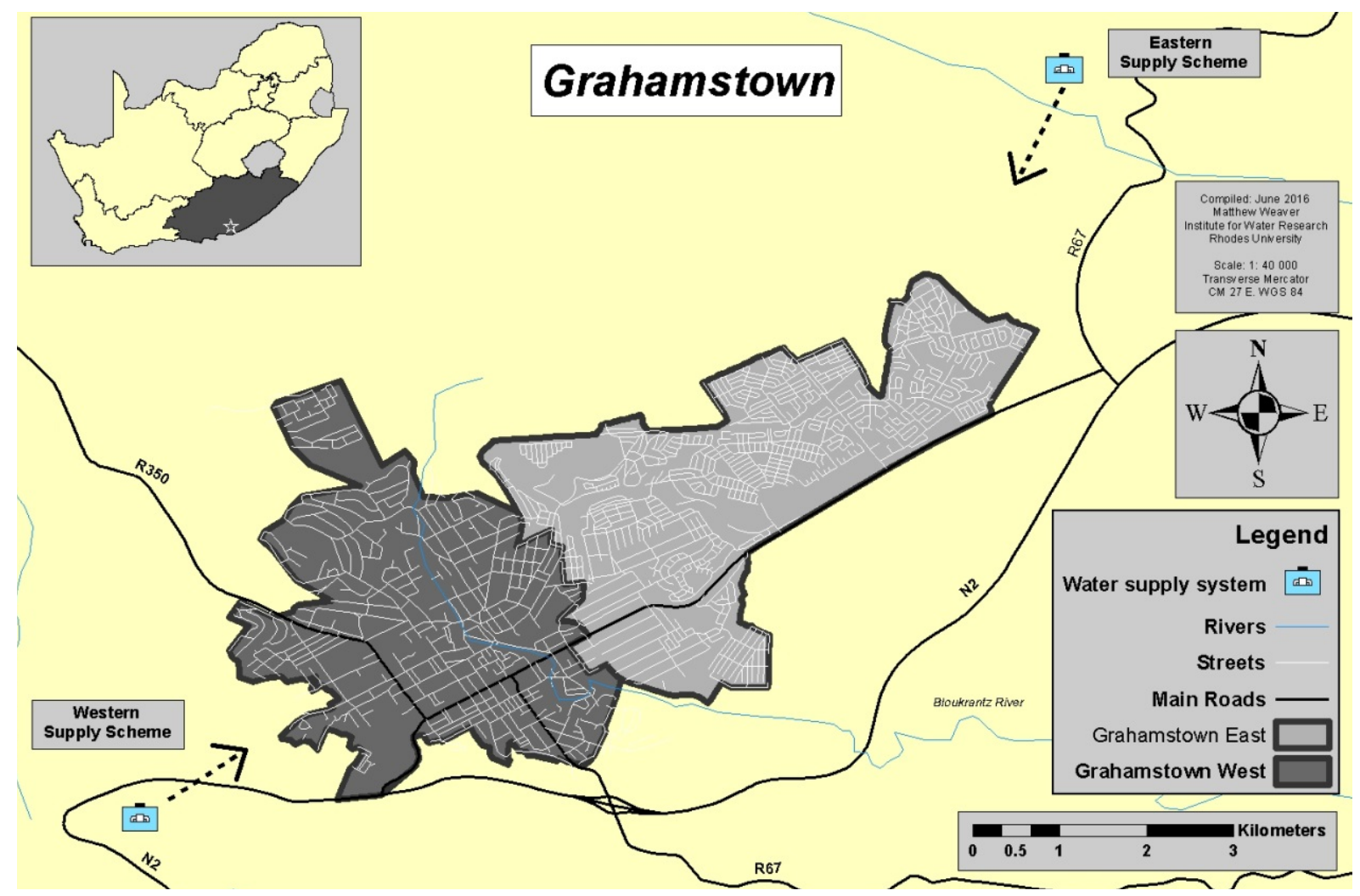

Figure 1

Map of Grahamstown depicting the two recognised areas Grahamstown West receiving water from the western supply system and the former township, Grahamstown East, receiving water from the Orange/Fish River inter-basin transfer scheme via the eastern water supply system

prominent. Although water quality is a significant issue in its own right, it is beyond the scope of this study, which concentrates on water supply.

The MLM has experienced repeated water supply issues over the past two decades; indeed, historical records show that water supply issues have plagued Grahamstown since the inception of the town in 1813 (Mullins, 2011). Water outages, in conjunction with public perceptions of poor water quality, have resulted in increasing public frustration and a breakdown of trust between the public and the MLM, culminating in a number of service delivery protests, peaking in August 2013 (Grant, 2014) with the MLM subsequently branded as dysfunctional by the Provincial Government (Dayimani, 2015; PSAM, 2015). The MLM 'water crisis' (Office of the Administrator, 2015) drew the attention of the Office of the President and led to an intervention by the Presidential Infrastructure Co-ordinating Committee to investigate issues and diagnose solutions (Yako, 2015). This was followed by the implementation of the Makana Water Intervention co-ordinated by the DWS. The water crisis was one emergent manifestation of the dysfunctional MLM system that contributed to the municipality being placed under political administration in October 2014 and in the care of a provincially appointed Administrator.

The WSD challenges in the MLM can largely be attributed to a suite of interconnected and multivariate historical, technological, political, institutional, social, economic and hydrological issues (Yako, 2015). Indeed the combination of these issues has resulted in the emergence of a complex problem (Cilliers et al., 2013) with no single solution, such that the MLM was unable to resolve the issue without additional assistance.

The Institute for Water Research at Rhodes University conducted the Makana Case Study as part of a larger Water Research Commission-funded project, entitled 'Towards practicing a new paradigm (TPNP)'. The TPNP project sought, among other things, to develop different forms of praxis to improve integrated water resource management processes in South Africa. The participatory action research process conducted with the civil society organisation (CSO) Water for Dignity (WfD) was the main research focus of the Makana Case Study. The perspective guiding the systems inquiry of the MLM C-SES presented here is that of WfD, and that of its members, in the process of addressing household water supply issues in Grahamstown East (Box 1).

\section{SHOWCASING A SYSTEMS INQUIRY METHODOLOGY}

The following section uses the MLM C-SES case study to outline the analytical process of conducting a systems inquiry. The key steps outlined include: defining the situation of interest and bounding the system, identifying elements and relationships, and describing problematic relationships in a system. 
BOX 1: DESCRIPTION OF THE CIVIL SOCIETY ORGANISATION WATER FOR DIGNITY (WFD)

Water for Dignity is a civil society group that at its most active comprised five members, and emerged and practised in Grahamstown East in response to WSD issues. Their emergence was facilitated, and practice supported, by the Institute for Water Research and Khulumani Support Group (a social justice non-governmental organisation) partners. This support ranged from advice, participation and collaboration to financial support in the form of stipends. The WfD group conceptualised four initiatives to address prominent water service delivery issues facing Grahamstown East residents. These included:

1. Citizen Report Cards: household surveys exploring water service delivery experiences of Grahamstown East residents

2. Community Water Forums: water-related neighbourhood-based communication hubs serving as information pathways between the MLM and Grahamstown East residents

3. Emergency Water: installation of water storage infrastructure (5 $000 \mathrm{~L}$ street tanks and $210 \mathrm{~L}$ barrels) on streets and households to serve as an emergency water supply during instances of water supply shortfall

4. School Water Forums: awareness raising and encouraging best practices relating to hygiene, water conservation and catchment health

\section{Defining the situation of interest and bounding the system}

Systems practitioners are restricted by constraints of knowledge, priorities, resources, motivations and perspectives and therefore cannot truly conduct a fully holistic systems inquiry or solve all the problems (Williams and Van 't Hof, 2016). It is therefore important to define a situation of interest and then negotiate the boundaries of the system of interest (decide which aspects to consider at a defined scale as well as decide which aspects will not be considered). The situation of interest guiding the systems inquiry into the MLM C-SES is household WSD in Grahamstown East. With the situation of interest defined, the observer can bound the system, including relevant components, into a system of interest - the MLM C-SES. There are key social (institutional arrangements such as the Water Service Provider and the Water Board) and ecological components (quaternary and quinary catchments) important to household WSD that should be included in the MLM C-SES (indicated in the shaded area in Fig. 2). The MLM C-SES is an open system in that it is affected by and affects components of the larger complex social-ecological system that fall outside of its boundary (Ison, 2010). Components outside of the boundary that still interact with components within form part of the wider environment (Ison, 2010). The interaction between system components and the environment can influence the behaviour of the system of interest.

In C-SESs there is typically a mismatch between varying social and ecological scales (Pollard and Du Toit, 2008). In this case, the boundaries of the various catchments do not align with municipal boundaries responsible for their management. This mismatch adds additional complexity to water management systems (Fig. 2).

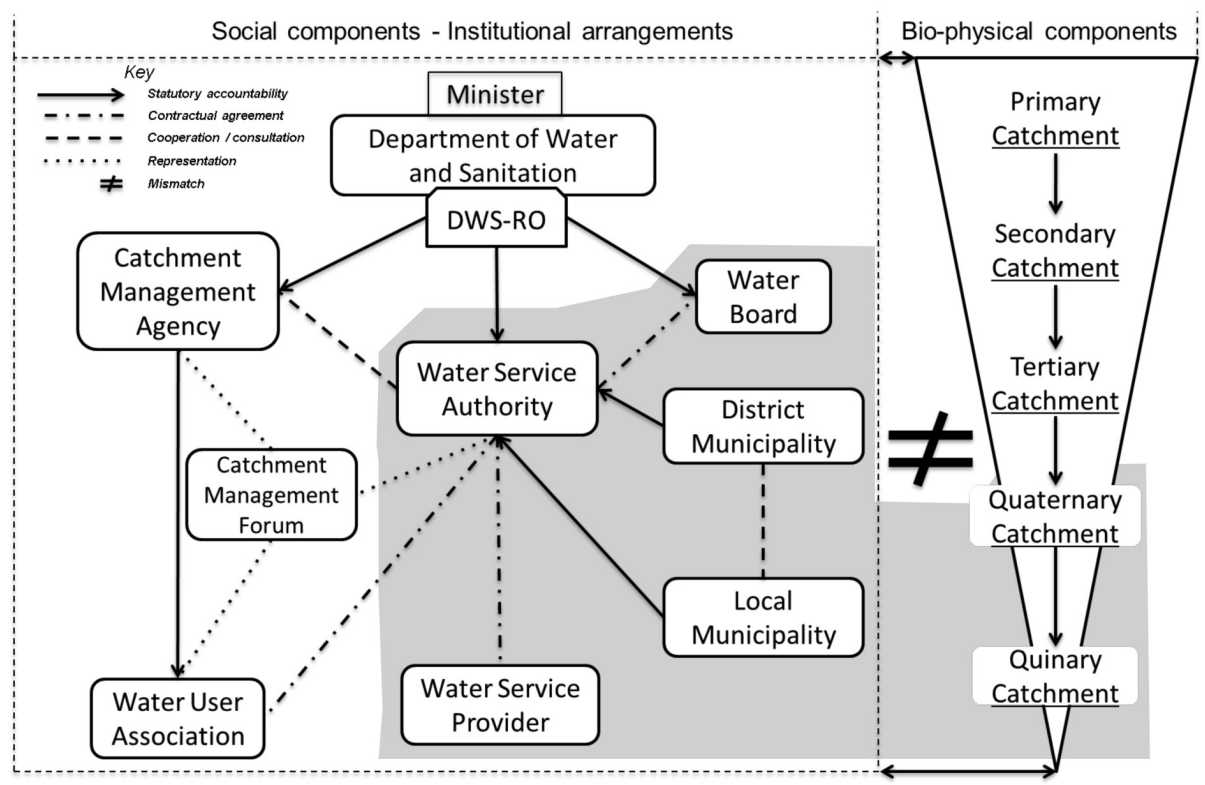

Figure 2

A conceptual heuristic of the social and ecological components of the South African water management system. Different relationships between institutional actors are indicated. The scales at which the institutional arrangements and the ecological components occur do not align neatly (adapted from Clifford-Holmes, 2015). The institutional arrangements and catchment scale relevant to this case study are encompassed within the shaded area. 


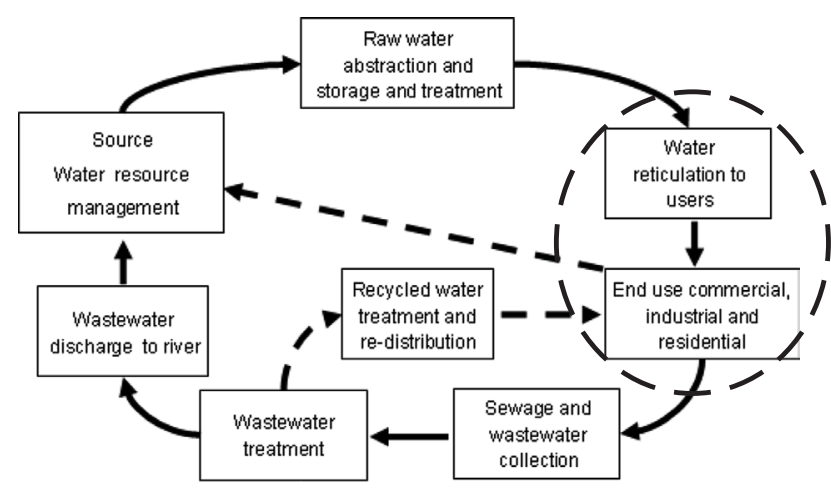

Figure 3

A typical urban water system. Although the Makana Local Municipality lacks the capacity, ideally wastewater is treated to a level that can then be recycled for reuse by consumers (dashed line). In some instances, there is occurrence of lawful and unlawful discharge by users directly into water sources (dashed line). Of particular interest to this study is household water service delivery (encircled).

The institutional arrangements and bio-physical catchment scales apply generally (except in the large Metropolitan areas) and nationally in South Africa (Fig. 2). The particular subsystem of interest for this systems inquiry relates to water service delivery in Grahamstown East; therefore it is useful to further bound the MLM C-SES specifically within the urban water cycle (Fig. 3).

Once the situation of interest has been identified and the system of interest has been bounded, the important elements and their relationships can be identified. The boundaries of a system of interest are constantly re-negotiated as the perspectives, knowledge and priorities of different observers are considered.

\section{Elements and relationships evident in the MLM C-SES}

The systems inquiry process then moves to defining the key elements, grouped into sub-systems that are relevant to the situation of interest. Typical relationships between elements are described, taking care to link relationships described to theory, or to notice where theoretical relations are not evident in practice. The Rogers and Luton (2011) VSTEEP categories (values, social, technological, economic, environmental/ biophysical and political) were used as a check for providing a full contextual description.

Government, technical, civil society and research were identified as relevant sub-systems, each with specific elements and relationships related to WSD in the MLM C-SES.

\section{Government sub-system - oversight and administration of household WSD}

The local government has the primary responsibility for providing household water services (RSA, 2000). In the MLM C-SES the African National Congress is the political party that governs the MLM and is ultimately responsible for overseeing water service delivery to Grahamstown households. The MLM here has dual roles as Water Services Provider and the selfregulatory role of Water Services Authority. The institutional structure, actors and relationships within the MLM are depicted in Fig. 4.

To carry out their responsibility, the MLM has different relationships with other key elements:
- The Municipal Work-Streams - temporary stakeholder engagement platforms implemented by the Administrator via the Makana Water Intervention (see Yako, 2015), with advisory capacity to MLM and statutory accountability to the Administrator as the intervening authority (G1, G4). Relationships between elements that are depicted in the systems heuristic (Fig. 5) are referenced in the sub-system narrative as codes in brackets according to the sub-system they apply to (e.g. Government (G), Technical (T), Civil Society (CS) and Research sub-systems (R). For example, G1 refers to the advisory relationship between Municipal Work-Streams and local government actors responsible for water service delivery-related issues in Grahamstown East)

- Sarah Baartman District Municipality (DM) - oversight, support, consultation, cooperation and statutory accountability (G3)

- Eastern Cape Provincial Government - support, consultation, cooperation and statutory accountability (G4)

- Department of Cooperative Governance and Traditional Affairs (COGTA) - support, consultation and funding (G5)

- Department of Water and Sanitation (DWS) - oversight, support and statutory accountability (as WSA) (G6)

\section{Technical sub-system - water supply system}

- Technical infrastructure (dams, water and waste water treatment works, reservoirs, pipes, valves, meters and taps) - maintained and operated by the MLM and Amatola Water (T1)

- Two water supply systems: (i) The Orange-Fish River Inter-Basin Transfer (IBT) Scheme run by the DWS who are under a contractual agreement to supply raw water (3000 ML/d allocation). Water is treated and stored for reticulation in reservoirs (18.5 ML capacity) mainly to service Grahamstown East (78\% of the population) (with the capability of supplementing Grahamstown West when necessary). (ii) The western water supply system, which services Grahamstown West (22\% of the population) from MLM-owned dams and reservoirs (11.76 ML capacity) (Desai et al., 2012) - Amatola Water (the regional Water Board of the Eastern Cape) has a services contract with the MLM to maintain and operate local components of the two supply systems (T3, T4, T5, T6, T7)

- Amatola Water - contractual agreement (services contract) with the MLM acting as the Water Services Authority to manage bulk water supply (S2, T4)

- Technical consultants MBB Engineering - intermittent contractual agreements with the MLM (T2)

\section{Civil society sub-system - water consumers}

Grahamstown East and West are two areas receiving different water supplies (Fig. 4). All residents can participate in municipal stakeholder engagement processes and have a statutory accountability to pay for municipal services that they receive, unless they qualify for free basic service allowances (RSA, 2000). The two areas are viewed as separate elements:

- Grahamstown East: 'township' area comprising mostly Black residents (99.3\%) with a high poverty and unemployment rate (49\%) (Stats SA, 2011) (CS1)

- Grahamstown West comprises the town's central business district and economic hub, has a low unemployment rate (9.4\%), and contains the majority of the town's affluent residents, $97.3 \%$ of the White population and an increasing number of Black residents (now $62.5 \%$ of Grahamstown West residents) (Stats SA, 2011) (CS1) 


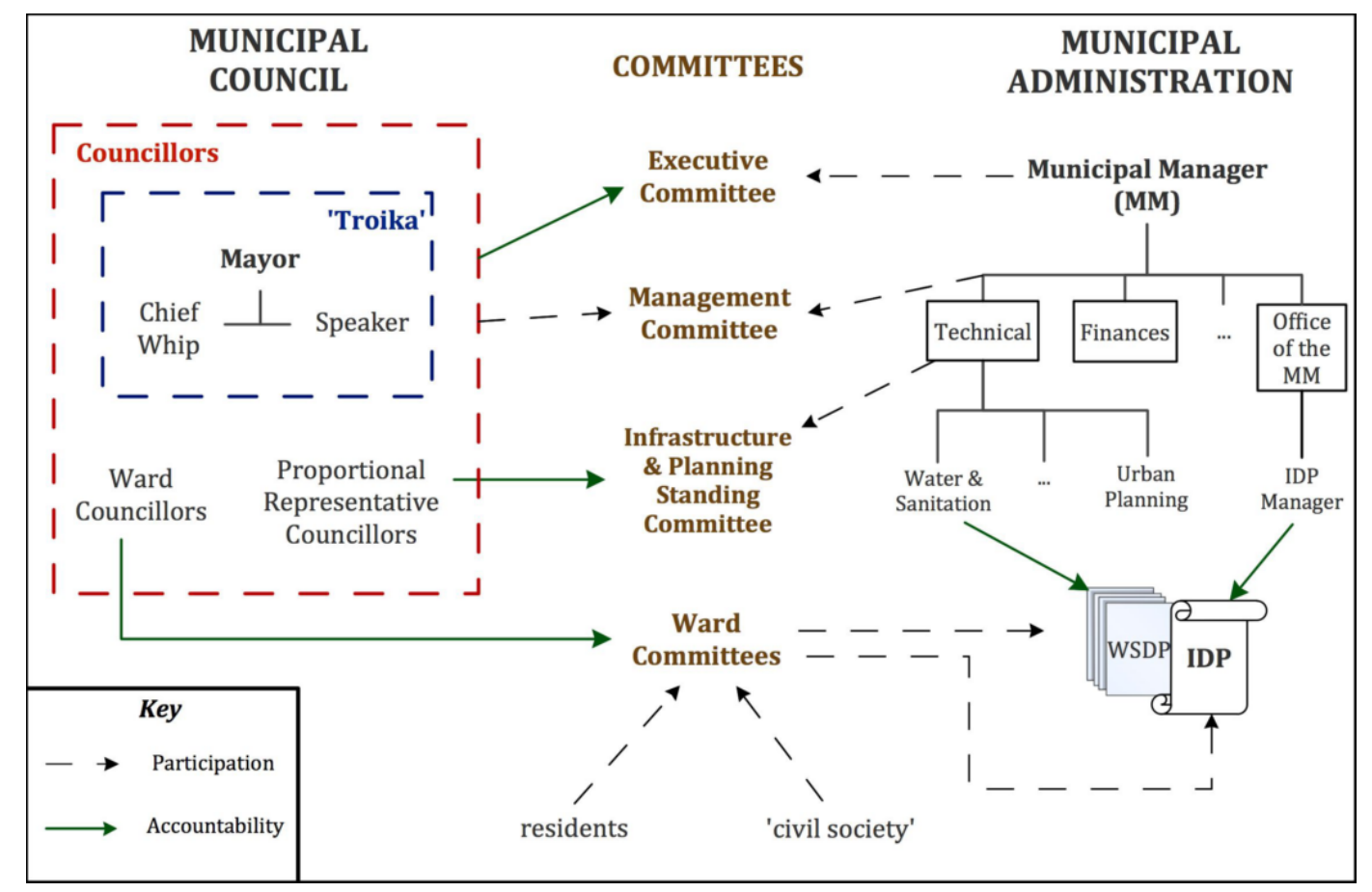

Figure 4

A systems diagram that depicts the institutional structure, actors and decision-making pathways within most local municipalities, the Makana Local Municipality included. The diagram shows the relationship between the political oversight by the municipal council and various committees over the municipal administration responsible for carrying out the water service delivery responsibilities of the municipality. (WSDP - Water Services Development Plan; IDP - Integrated Development Plan) (Source: Clifford-Holmes, 2015, p.143).

- Of relevance was the Kowie Catchment Campaign, an active CSO in Grahamstown West, which participated in MLM catchment-related processes and addressed local catchment health-related issues (CS2)

\section{Research sub-system - research related to household WSD}

Research was a key sub-system in the MLM C-SES, since understanding the role of CSOs in addressing local WSD was the research focus that this systems description informed. The key elements included:

- The CSO, Water for Dignity - who collaborated with multiple other actors to improve water service delivery to households in Grahamstown East (Box 1) (R1, R2)

- The Institute for Water Research (IWR) within Rhodes University (RU) - researchers conducted research into and participated in water-related processes in the MLM (S3); and conducted participatory action research into, as well as supported, collaborated and participated in WfD practices (R2)

- Khulumani Support Group - a non-governmental organisation that partnered and collaborated with WfD (R1)

- Unilever South Africa - contributed financially to particular IWR and WfD projects (R6)

- Other societies, groups and organisations that had relationships with WfD: Wildlife and Environmental Society of South Africa (WESSA) - funding, participation and collaboration (R5); Galela Amanzi, a student activist group - collaboration (R7); and MobiSAM, a RU Computer Science project - collaboration (R4)
To better understand and conceptualise the MLM C-SES, we found it helpful to combine the cumbersome, but necessary, narrative description of the system with a systems heuristic (Fig. 5). This systems heuristic was developed as an emergent outcome of engaging in the MLM C-SES description to better conceptualise the sub-systems, elements and their interrelations. In addition, its development proved a fundamental step to understanding and bounding the system and to guide further research relating to CSO engagement in WSD in Grahamstown East.

\section{Problematic relationships evident in the MLM C-SES}

The WSD complex problem in the MLM C-SES can partly be attributed to relationship-issues between system elements. For the MLM water management C-SES to effectively fulfil its responsibility of supplying potable water to households, 'healthy' relationships need to occur within and between these elements. These relationships have been grouped into problematic socio-economic, technological, economic and political relationships.

Problematic socio-economic relationships include high unemployment $(39.3 \%$ in 2011$)$ and poverty (39.4\% in 2010$)$ rates (Stats SA, 2011) and, as a result, many residents are unable to pay for water services. Makana has poor revenue collection due to non-payment and a dysfunctional billing system (Hamer, 2016; Yako, 2015). A revenue collection deficit and inefficient collection systems restrict the MLM's ability to support staff to operate, maintain and upgrade the reticulation system (Yako, 2015). The MLM indigent register is not up to 


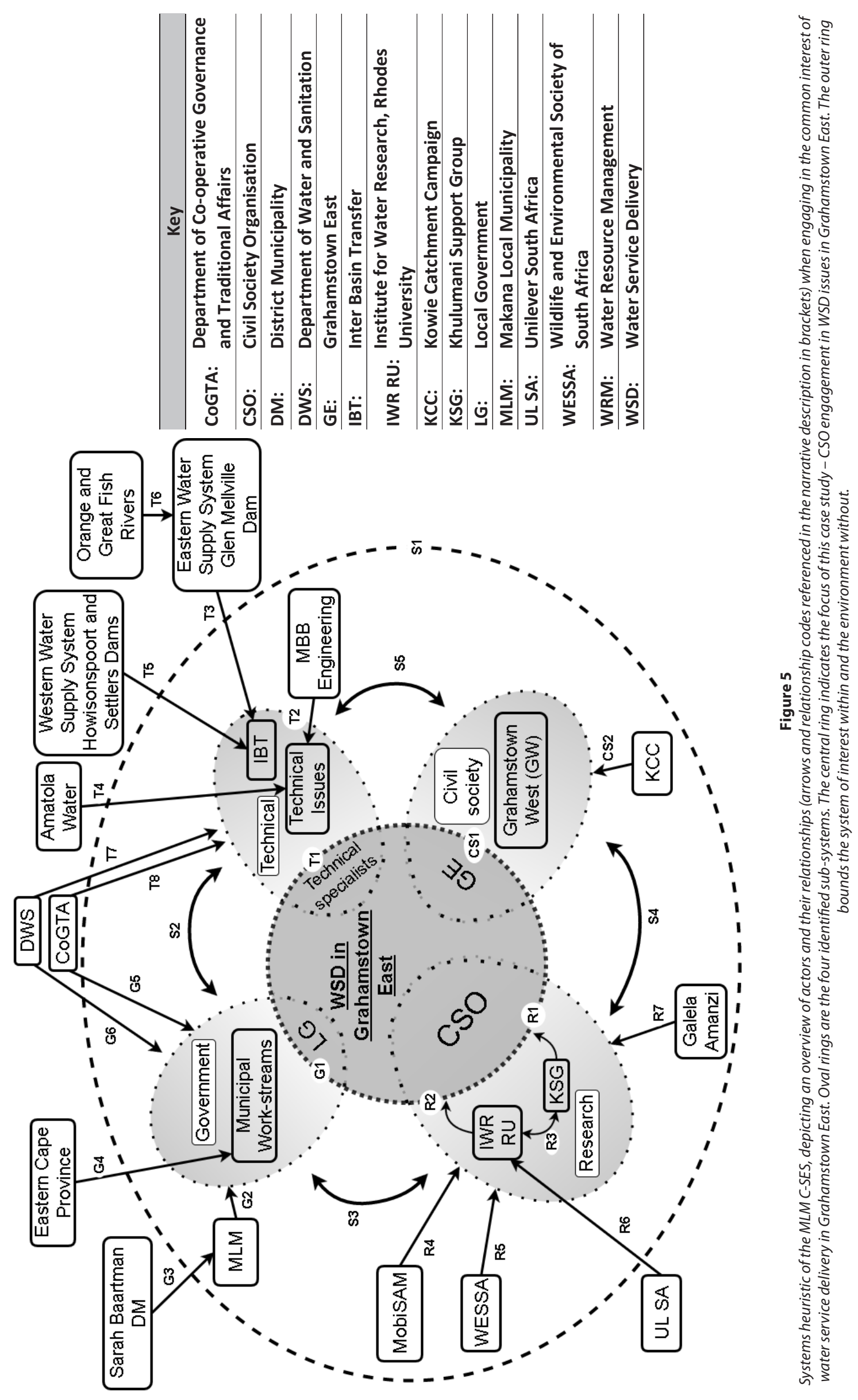


date (Makana Municipality, 2012) - the number of indigent households determines the equitable share allocation to support free basic services. Challenges lie with poor people not registering and employed people who are able to pay for services claiming indigence (Mngxitama-Diko, 2012). Reconstruction and Development Programme (RDP) houses require household water connections, and this places additional demand on the already overstretched water supply system.

Problematic technological relationships include the MLM and the institutions that they depend upon to operate and maintain the water reticulation system, as well as the ecological and biophysical characteristics of the catchment (variable rainfall and intermittent droughts). The lack of proper mapping, maintenance and upgrading of the aging reticulation system over the years, combined with the loss of institutional knowledge within the MLM, has resulted in recurring infrastructure failure (Mullins, 2011; Makana Municipality, 2012). The high salinity of the water from the Orange/Fish River Inter-basin Transfer Scheme incurs high treatment costs and therefore economic implications (Office of the Administrator, 2015). This salinity also has socio-political implications - e.g., the perception that Grahamstown East receives poorer 'salty' water and Grahamstown West receives good quality, 'sweet' water. The topography of Grahamstown is variable, requiring extensive pumping to supply high-lying areas (ibid). This further leads to large pressure differences which are managed with complicated valve systems. Difficulties with managing this system in the context of aged infrastructure often leads to further pipe bursts and water reticulation system failure.

Problematic economic relationships are a consequence of poor financial management within the MLM (G2), such as difficulties with paying salaries to municipal staff and creditors such as the DWS (for raw water received from the Orange/Fish IBT) (G6), Amatola Water and MBB Engineering (Yako, 2015), poor management of the Indigent control system (MngxitamaDiko, 2012), and several failed Auditor-General reports (Yako, 2015). These relationships are important in securing external funding through governmental grant applications and water tariff collection from consumers. Contributing factors to this financial mismanagement include the lack of sufficient financially-qualified staff, underspending on budgets (Yako, 2015) and corruption (Kabuso, 2014). Mismanagement of funds leads to less money being available to maintain, upgrade and operate the water reticulation system (S2).

Problematic political relationships, both within and outside the MLM, relate to the lack of effective political oversight which MLM councillors should provide to the municipal administration responsible for fulfilling municipal functions (G2). This ultimately resulted in the MLM being placed under political administration in 2014 (Yako, 2015) (G4). The poor performance of the MLM staff and processes is evident in the self-assessment facilitated by the DWS in 2014 (Table 1).

The political arm of the MLM is further influenced by the Sarah Baartman DM (G3), the Eastern Cape Provincial Government (G4) and the National Government, particularly the DWS (G6) - maintaining effective communication channels and relationships between these spheres enables effective integrated governance.

The relationship between the MLM and citizens is formally facilitated through ward committees (RSA, 1998b). In the MLM many of the 14 wards do not have functional ward committees for reasons ranging from lack of communication equipment; trust breakdown between citizens, ward councillors and ward committee members; and poor capacity and motivation of ward staff; to internal political infighting (Office of the Administrator, 2015; Yako, 2015). The resultant communication breakdown has alienated a large proportion of the community, leading to distrust and the general lack of support for existing municipal processes (Yako, 2015). Furthermore, this communication breakdown has also restricted the MLM's ability to communicate successful and positive actions that have improved local water supply.

This system's description is by no means all encompassing, but it does provide a rich picture of the elements and relationships comprising the MLM C-SES and the greater environment within which it falls. A systems description is always subjective and at best a simplified model of reality that, among other things, enables action towards positive change in a situation of interest. The description has also highlighted some of the problematic relationships in the system that contributed to the complex WSD problem in the MLM.

\section{DISCUSSION}

This paper motivates for a systems approach to addressing complex social-ecological problems such as municipal WSD. Moreover, it describes an important methodology for conducting a systems inquiry, methodological steps that are often assumed in much of the literature. A clear exposition of this methodology, namely, steps of defining a situation of interest, bounding a system of interest and identification of elements and relationships, was the first aim of this paper. The application of this methodology through the example of the case study of the underlying WSD problems in the Makana Local Municipality satisfied the second aim. Developing a systems understanding of a C-SES context is an important step to enable better access to research questions into various aspects of the system. The example provided in this study guided and supported research into the emergence and practice of the CSO, Water for Dignity. This systems understanding helped to focus $\mathrm{CSO}$ research and informed the evaluation of the impact the CSO had on household WSD in Grahamstown East.

The systems description and the emergent systems heuristic is essentially a model of the MLM C-SES, a 'good enough' representation of the real-world system (Ison et al., 2013). The paper recounts a systematic approach to conceptually modelling a C-SES using the case of the MLM C-SES.

The purpose of undertaking a systems description (e.g. to inform the situation of interest - research into CSO practice to address household WSD) ultimately guides the research process, and determines the extent of understanding required (Cilliers et al., 2013). The extent of this description was at the MLM level, smaller yet at the scale of Grahamstown East.

TABLE 1

Makana Local Municipality Annual Municipal Strategic SelfAssessment 2014 (Source: Office of the Administrator 2015, p.4). Low vulnerability (75-100\%), moderate vulnerability $(60-75 \%)$, high vulnerability $(50-60 \%)$, extreme vulnerability $(0-50 \%)$.

\begin{tabular}{|l|c|}
\hline Indicator description & Score \\
\hline Management skill level (technical) & $35 \%$ \\
\hline Staff skill levels (technical) & $40 \%$ \\
\hline Infrastructure asset management & $10 \%$ \\
\hline Operation and maintenance (O \& M) of assets & $40 \%$ \\
\hline Financial management & $30 \%$ \\
\hline Revenue collection & $15 \%$ \\
\hline
\end{tabular}


With this purpose as the guiding thread, it was useful to consider the landscape scale and define the water resource management environment in which the system of interest, the MLM C-SES, exists. This environment included the institutional water resource management landscape and the biophysical catchment landscape, both inherently complex, interlinked and occurring at different scales (not always aligned, see Fig. 2) (Pollard and Du Toit, 2008). As it is only possible to focus on limited characteristics of a complex system (Cilliers et al., 2013), it is useful to bound, or frame a system of interest, in this case, household WSD in the MLM C-SES. This bounding does not ignore the larger system environment, as complex systems are open systems (Cilliers, 2000) behaviour evident in the system of interest may be in response to relationships from the environment/larger system, e.g., high treatment costs of Grahamstown bulk water due to the high salinity of water emanating from the Orange/Fish River transfer scheme. These interrelations need to be acknowledged.

Unpacking the MLM C-SES involved highlighting and describing sub-systems (government, technical, civil society and research) and the interacting elements they comprise. Understanding how the system functions lies in the interactions or relationships between elements (Palmer et al., 2015), the state and health of which determine the functional efficiency and sustainability of the system. This is evident in the MLM C-SES where the combination of multiple, 'unhealthy' relationships between sub-systems and elements resulted in water supply challenges. The systems description showed these relationships to range from technological (aging infrastructure and lack of maintenance), socio-economic (unemployment and non-rate payment), economic (financial mismanagement and non-payment of creditors) and bio-physical (variable rainfall and intermittent droughts) to political (lack of sufficiently qualified and motivated municipal staff and councillors as well as the lack of collaboration between political actors and partners). Nkhata et al. (2008) provide a conceptual premise for understanding and analysing long-term social relationships key to effective, collaborative C-SES management.

Consequently, WSD in the MLM C-SES that has no single or simple solution; in addition any solution would inevitably cause further problems (Cilliers, 2000). Although this systems description did not offer potential interventions that could alleviate the WSD problem in the MLM C-SES, it does provide the foundation for designing interventions. Adopting a systems thinking approach and doing the initial systems inquiry steps towards understanding the system provides an effective foundation from which to intervene and influence the system towards an improved state (Berkes et al., 2003; Ostrom and Cox, 2010; Audouin et al., 2013; Binder et al., 2013; Rogers et al., 2013).

Human limitations to comprehensively understand a complex system (cognitive ability, time, financial resources, etc.) make it necessary to focus on the level of detail necessary to inform decision making. This was achieved by bounding the system to include and describe four key sub-systems relevant to WSD in Grahamstown East. Conceptualising this reduced level of detail so as to inform decision making (e.g. defining which questions, elements and relationships to interrogate) is greatly enhanced through the use of effort-reduction tools, or heuristics (Shah and Oppenheimer, 2008). Simon (1990), who conducted seminal work on heuristics, described them as 'methods for arriving at satisfactory solutions with modest amounts of computation'. The heuristic depicting the MLM C-SES (Fig. 5) was an emergent property of effort placed into developing an understanding and description of the system. The process of emergence is consistent with the complex nature of SESs (Cilliers, 2000; Rogers et al., 2013). In combination with the deeper narrative, the heuristic provided: a useful conceptual overview of the system; an accessible tool to bring different perspectives to bear and form a common understanding of the system (Cilliers et al., 2013); and, importantly, a guide for future CSO-related research.

This system's description was conducted from the perspective of a few researchers embedded in the MLM C-SES, who were interested in a local CSO. The knowledge created was relevant to that interest. Despite this, incorporating different perspectives into the systems description process would likely have resulted in a richer, more complete systems understanding.

The work of providing a rich understanding of the C-SES context of the MLM water management system provides an important base for the investigation of other questions. For example, this MLM C-SES description provided the basis from which to investigate the mechanisms, elements and relationships that supported and constrained the emergence, practice and process of learning for the CSO, Water for Dignity, in response to WSD issues in the MLM. Another question that resulted from this description related to the role of CSOs in enabling improved democratic water governance at a local government scale. Furthermore, this understanding highlights problematic relationships in the MLM C-SES as potential research focal areas and points of intervention where household WSD may be improved.

In addition, the systems approach taken can be extended to answer deeper questions regarding transformation at a local government scale. Ison (2010) suggests that the combination of people's changes in practice and changes in understanding in relation to a situation of interest (e.g. household water supply) results in an improved situation and transformation.

Given the complexity of the MLM SES, further research could use this description as a base to deepen the understanding of the roles that other sub-systems (civil society, technical, political and research) play in improving WSD within the C-SES.

The systems inquiry methodology presented can be applied to other municipal contexts. Indeed, problems associated with complex water management systems apply to many South African municipalities and have elicited reactionary or firefighting responses (Clifford-Holmes et al., 2016) as opposed to proactive management responses. Decision makers responsible for the management of water service delivery systems are often overwhelmed by the complexity and multitude of problems that manifest in these systems. Adopting the key foundational steps of a systems inquiry approach to define and understand a complex water management system provides a manageable way for decision makers to make informed interventions to improve the function and effectiveness of a system. Furthermore, a systems inquiry process can eliminate silo-thinking by: bringing multiple perspectives to bear, developing a common understanding of the system and key problems, promoting the co-creation of interventions, and promoting mutual accountability of decision makers.

This methodology was derived from a single case study. To further test the applicability and usefulness of this methodology it would be valuable to apply it in multiple case studies at different local government scales and contexts. 


\section{ACKNOWLEDGEMENTS}

We would like to thank the two anonymous reviewers for their insightful comments and recommendations that played an important role in strengthening this paper.

\section{REFERENCES}

AUDOUIN M, PREISER R, NIENABER S, DOWNSBOROUGH L, LANZ J and MAVENGAHAMA S (2013) Exploring the implications of critical complexity for the study of social ecological systems. Ecol. Soc. 18 (3) 12. https://doi.org/10.5751/es-05434-180312

BERKES F, COLDING J and FOLKE C (2003) Navigating SocialEcological Systems: Building Resilience for Complexity and Change. Cambridge University Press, Cambridge. 393 pp.

BIGGS RO, RHODE C, ARCHIBALD S, KUNENE LM, MUTANGA SS, NKUNA N, OCHOLLA, PETER OP and PHADIMA LJ (2015) Strategies for managing complex social-ecological systems in the face of uncertainty: Examples from South Africa and beyond. Ecol. Soc. 20 (1) 52. https://doi.org/10.5751/es-07380-200152

BINDER C, HINKEL J, BOTS PWG and PAHL-WOSTL C (2013) Comparison of frameworks for analyzing social-ecological systems. Ecol. Soc. 18 (4) 26. https://doi.org/10.5751/es-05551-180426

BISWAS AK (2008) Integrated water resources management: is it working? Int. J. Water Resour. Dev. 24 (1) 5-22. https://doi. org/10.1080/07900620701871718

BRISTOW KL, MARCHANT SM, DEURER M and CLOTHIER BE (2010) Enhancing the ecological infrastructure of soils. In: Proceedings of the 19th World Congress of Soil Science, Soil Solutions for a Changing World, 1-6 August 2010, Brisbane.

CILLIERS P (2000) What can we learn from a theory of complexity? Emergence 2 (1) 23-33. https://doi.org/10.1207/ S15327000EM0201_03

CILLIERS P, BIGGS HC, BLIGNAUT S, CHOLES AG, HOFMEYR JHS, JEWITT GPW and ROUX DJ (2013) Complexity, modelling, and natural resource management. Ecol. Soc. 18 (3) 1. https://doi. org/10.5751/ES-05382-180301

CLIFFORD-HOLMES JK (2015) Fire and water: a transdisciplinary investigation of water governance. $\mathrm{PhD}$ thesis, Rhodes University.

CLIFFORD-HOLMES JK, PALMER CG, DE WET CJ and SLINGER JH (2016) Operational manifestations of institutional dysfunction in post-apartheid South Africa. Water Polic. 18 998-1014. https:// doi.org/10.2166/wp.2016.211

DAYIMANI M (2015) Bhisho to guide Makana. URL: http://www. grocotts.co.za/content/news-bhisho-guide-makana-27-03-2015 (Accessed 14 May 2015).

DWA (DEPARTMENT OF WATER AFFAIRS, SOUTH AFRICA) (2013) National Water Resource Strategy. June 2013 Second Edition. Department of Water Affairs, Pretoria.

DESAI A, MALLORY S and BALLIM F (2012) Development of water supply and drought operating rules for stand-alone dams/schemes typical for rural/small municipal set-ups: Southern Cluster. Grahamstown System Operational Analysis Report.

FOLKE C (2003) Freshwater for resilience: a shift in thinking. Phil. Trans. R. Soc. Lond. B Biol. Sci. 358 (1440) 2027-2036. https://doi. org/10.1098/rstb.2003.1385

GRANT L (2014) Taking to the streets: Who is protesting and why? Mail and Guardian 28 April 2014. URL: http://mg.co.za/data/201404-28-taking-to-the-streets-who-is-protesting-and-why (Accessed 21 June 2015)

HAMER NG (2016) Personal communication, 5 February 2016. Mr Nick Hamer, Institute for Water Research (IWR), Rhodes University, Old Geology Building, Rhodes University, PO Box 94, Grahamstown, 6140, South Africa.

ISON R (2010) Systems Practice: How to Act in a Climate-change World. Springer, London. 340 pp. https://doi.org/10.1007/978-1-84996-125-7

ISON R, BLACKMORE C and IAQUINTO BL (2013) Towards systemic and adaptive governance: Exploring the revealing and concealing aspects of contemporary social-learning metaphors. Ecol. Econ. 87 34-42. https://doi.org/10.1016/j.ecolecon.2012.12.016

JÜRGENS U, DONALDSON R, RULE S and BÄHR J (2013) Townships in South African cities - literature review and research perspectives. Habitat Int. 39 256-260. https://doi.org/10.1016/j. habitatint.2012.10.011
KABUSO (2014) Report on a forensic investigation into various matters at the Makana Local Municipality. URL: www.makana. gov.za/wp-content/iuploads/2013/06/kabuso-report-document.pdf (Accessed 15 June 2015).

KING J and PIENAAR H (2011) Sustainable use of South Africa's inland waters: A situational assessment of Resource Directed Measures 12 years after the 1998 National Water Act. WRC Report No. TT 491/11. Water Research Commission, Pretoria.

LANG DJ, WIEK A, BERGMANN M, STAUFFACHER M, MARTENS P, MOLL P, SWILLING M and THOMAS CJ (2012) Transdisciplinary research in sustainability science: practice, principles, and challenges. Sustainability Sci. 7 25-43. https://doi. org/10.1007/s11625-011-0149-x

MAKANA MUNICIPALITY (2012) Makana Municipality Annual Report 2011 | 2012.

MNGXITAMA-DIKO A (2012) "We need more money for the poor" Mayor. URL: http://www.grocotts.co.za/content/we-need-moremoney-poor-mayor-15-11-2012 (Accessed 1 June 2016).

MULLINS RLG (2011) Grahamstown's Water Supply: a brief history from 1812 to 2008. Ann. E. Cape Mus. May 2011 (7) 1-64.

MDB (Municipal Demarcation Board) (2013) MDB Municipal Capacity Assessment 2011 Comparative Report Card covering the 2010/2011 Municipal Financial Year Makana Local Municipality.

NKHATA AB, BREEN CM and FREIMUND WA (2008) Resilient social relationships and collaboration in the management of social-ecological systems. Ecol. Soc. 13 (1). https://doi.org/10.5751/ ES-02164-130102

Office of the Administrator (2015) Makana Water and Sanitation Indaba. Grahamstown.

OSTROM E and COX M (2010) Moving beyond panaceas: a multitiered diagnostic approach for social-ecological analysis. Environ. Conserv. 37 (4) 451-463. https://doi.org/10.1017/ S0376892910000834

PAHL-WOSTL C (2007) Transitions towards adaptive management of water facing climate and global change. Water Resour. Manage. 21 (1) 49-62. https://doi.org/10.1007/s11269-006-9040-4

PALMER CG, BIGGS R and CUMMING GS (2015) Applied research for enhancing human well-being and environmental stewardship: Using complexity thinking in Southern Africa. Ecol. Soc. 20 (1) 53 https://doi.org/10.5751/ES-07087-200153

POLLARD S and DU TOIT D (2008) Integrated water resource management in complex systems: How the catchment management strategies seek to achieve sustainability and equity in water resources in South Africa. Water SA 34 (6) 671-679.

psam (Public Service Accountability Monitor) (2015) Makana rescue was invalid. URL: http://www.ru.ac.za/psam/latestnews/ (Accessed 14 May 2015).

RSA (Republic of South Africa) (1996) Constitution of the Republic of South Africa. No. 108 of 1996. Pretoria, South Africa.

RSA (Republic of South Africa) (1997) Water Services Act (Act No. 108 of 1997). Pretoria: Department of Water Affairs and Forestry.

RSA (Republic of South Africa) (1998) National Water Act (Act No. 36 of 1998). Pretoria: Department of Water Affairs and Forestry.

RSA (Republic of South Africa) (1998b) Local Government Municipal Structures Act (Act No. 117 of 1998). Government Gazette No. 19614, Cape Town, South Africa.

RSA (Republic of South Africa) (2000) Local Government: Municipal Systems Act (No. 32 of 2000). Cape Town. Government Gazette No. 21776. Government Printer, Cape Town, South Africa.

ROGERS KH, and LUTON R (2011) Strategic Adaptive Management as a framework for implementing Integrated Water Resource Management in South Africa. WRC Report No. KV 245/10. WRC, Pretoria.

ROGERS KH, LUTON R, BIGGS H, BIGGS RO, BLIGNAUT S, CHOLES AG, PALMER CG and ANGWE P (2013) Fostering complexity thinking in action research for change in socialecological systems. Ecol. Soc. 18 (2) 31. https://doi.org/10.5751/ ES-05330-180231

SHAH AK and OPPENHEIMER DM (2008) Heuristics made easy: an effort-reduction framework. Psychol. Bull. 134 (2) 207-222. https://doi.org/10.1037/0033-2909.134.2.207

SIMON HA (1990) Invariants of human behaviour. Annu. Rev. Psychol. 41 1-19. https://doi.org/10.1146/annurev.ps.41.020190.000245 
SLINGER JH, HERMANS LM, GUPTA J, VAN DER ZAAG P, AHLERS R and MOSTERT E (2011) The governance of large dams: A new research area. In: UNESCO Workshop Principles of Good Governance at Different Water Governance Levels: Colloquium, 22 March 2011, Delft, The Netherlands. 33-44.

STATS SA (Statistics South Africa) (2011) Interactive data. URL: www.statssa.gov.za/?page_id=1417 (Accessed 15 January 2016).
SWILLING M and ANNECKE E (2012) Just Transitions: Explorations of Sustainability in an Unfair World. UCT Press, Cape Town. 360 pp. WILLIAMS B and VAN 'T HOF S (2016) Wicked Solutions: A Systems Thinking Approach to Complex Problems ( $2^{\text {nd }}$ edn). Bob Williams. $90 \mathrm{pp}$.

YAKO P (2015) Makana Local Municipality Intervention Final Report. Zenande Leadership Consulting. April 2015. 